\title{
Adhesion at asphalt-aggregate interface through surface energy
}

\author{
Ana Sofia Figueroa Infante ${ }^{1}$, Fredy Reyes Lizcano ${ }^{2}$, Néstor Cely Leal ${ }^{3}$
}

\author{
${ }^{1}$ La Salle University, Bogotá - Colombia, afigueroa@unisalle.edu.co \\ 2Javeriana University,Bogotá - Colombia, fredy.reyes@javeriana.edu.co \\ 3Javeriana University,Bogotá - Colombia, nestorleal90@gmail.com
}

\section{Recebido:}

3 de junho de 2019

Aceito para publicação:

11 de janeiro de 2020

Publicado:

15 de maio de 2020

Editor de área:

Kamilla Vasconcelos

\section{Keywords:}

Moisture Damage,

Adhesion,

Cohesion,

Limestone,

Sandstone,

Surface Free Energy,

Humidity Damage Index(IDH).

\begin{abstract}
One of the most common problems pavements have is the loss of adhesion and cohesion due to moisture damage. Tropical countries and rainy seasons are some of the causes for this type of distress on roads. Another factor that has high influence in this damage is the mineralogy of the aggregate. This research shows the results of adhesion and cohesion between the aggregates from a limestone quarry and two types of sandstones from different quarries, highly used for roads projects from Colombia, and the asphalt $60-70(1 / 10) \mathrm{mm}$, same PG58-22.

For determining the adhesion and cohesion, Bitumen Bond Strength tests were made for dry and wet conditions. In addition, the Surface Free Energy was measured for the aggregates and the asphalt. The results indicated that those type of aggregates are highly susceptible to moisture damage, due all values of humidity Index Damage (HDI) were less than 0,5 . This indicates that it is necessary to use modifiers for controlling the stripping of the pavements due to Moisture Damage.
\end{abstract}

DOI:10.14295/transportes.v28i2.2071

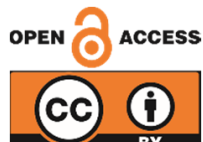

\section{INTRODUCTION}

The moisture sensitivity of asphalt mixes has been studied for many researchers since the first XX century quarter. However, most of the studies were focused on the simple visual inspection of this damage, so the results were just physical, but they never were based on quantify processes. One of the first studies that showed some moisture damage values took place in the Texas A\&M University, [1](Bhasin, Little, Vasconcelos, \& Masad, 2007), where were tested 12 asphalt mixtures carefully designed to represent a wide range of asphalt-aggregate interactions. Test results indicated that the moisture sensitivity of these mixtures correlates well with the energy parameters. They measured the work adhesion $W_{A S}$ which should be as high as possible to have the best adhesion behavior asphalt aggregate. On the other hand, a high value of $W_{A S}^{\text {wet }}$, wet work adhesion indicates a high thermodynamic potential for water to cause 
debonding, so it means that this value should be small as possible to reduce the moisture damage sensitivity. A generalized definition of damage is the system functionality loss [2](Caro, Masad, Bhasin, \& Little, 2008). At the same time, a definition of moisture damage is proposed by [3] (Kiggundu \& Roberts, 1988) as "the progressive functional deterioration of an asphalt mixture by the loss of adhesion between asphalt cement and the surface of Aggregate or loss of cohesive resistance of asphalt cement mainly in the face of water action ".

Moisture Damage within in liquid or vapor form finally affect the cohesion, which is the force of attraction in the same material, and the adhesion, which is the force of attraction between particles of different materials. [4] (Terrel, Al-Swailmi, Oregon State University., \& Strategic Highway Research Program (U.S.), 1994) indicate that water can affect cohesion in a lot of ways, including weakening by saturation of the mixture due to moisture.

Cohesion is a property that has influence on the asphalt mixture, beyond the area in which the properties of the interface are stronger.

The interest in this damage is evident because it has a great influence on the performance of the pavement. Despite tropical countries like Colombia have high temperatures, the rainy period and high humidity, take place almost the whole year. In fact, most of the damages on roads from Bogotá D.C., Colombia are due to the weather conditions and aging, (see FIGURE 1).

Flexible Pavements (Main Roads*)

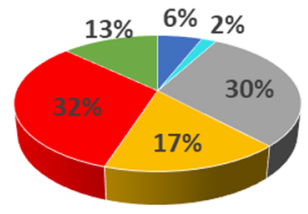

- Fatigue

- Aging

- Weather damages

$=$ Others

city from north to south and from east to west
Flexible Pavements (Local Roads**)

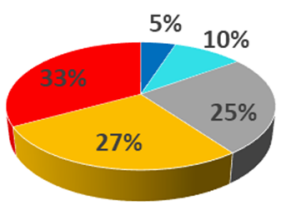

- Fatigue

- Aging

- Weather damages

- Rutting

- Constructions problems

- Others

Figure 1. Distresses on Flexible pavements from Bogotá D.C., Colombia, adapted data from Unidad de Mantenimiento Vial (UMV)

\section{BACKROUND}

[5] (Nicholson, 1932) was one of the pioneers of the first stripping studies dating back to 1932. He was the first researcher who called for the need to measure and take action on pavement moisture damage. In 1958, the American Society for Testing Materials (ASTM) held a symposium about the moisture damage of asphalt pavements called "Symposium on Effect of Water on Bituminous Paving Mixtures. Ed. 240", presented at the 19th session of the 61st annual meeting of the American Society for Testing Materials-ASTM, D-4 Committee. In this symposium, the problem of moisture in the pavements was discussed and presented as a subject that had to be investigated thoroughly from the problems of its determination in the laboratory w the problems of the field.

Another relevant study was the one developed by [6](McCann, Anderson-Sprecher, Thomas, \& Anderson-Sprecher, 2011) developed a study in which a statistical analysis was made on the influence of each property of the aggregate on the sensitivity to moisture damage. For the de- 
velopment of the research 11 types of aggregates were taken analyzing their physical and chemical properties. Eight types of asphalt concrete were made according to the Strategic Highway Research Program (SHRP). Tests carried out included freezing and thawing processes to determine the moisture sensitivity of mixtures when this physical phenomenon occurs. The most relevant indicator was insolubility in acid with calcium content, silicon content, loss by ignition, and zeta potential. Porosity was the second most important variable. One of the most significant predictors was acid insolubility. Some of the results indicated that aggregates containing a high percentage of iron, calcium and magnesium and a low percentage of silicon, aluminum and potassium are less susceptible to moisture damage. [7] (Mansour Solaimanian, David Fedor, Ramon Bonaquist, Ali Soltani, Vivek Tandon, Ilan Ishai, Gordon Airey, Art Johnston, Richard Davis, Gerald Reinke, Michael Heitzman, Frank Fee, Michael Dunning, n.d.) conducted a research to develop and improve the Environmental Conditioning System-ECS for analyzing the moisture sensitivity test in Hot Mixture Asphalt-HMA. This study was made in two phases. The first phase with a focus on flow time, flow number, and dynamic modulus concluded that the dynamic modulus test was the most appropriate of the three simple performance tests. The second phase worked on eight samples that were well known from its moisture damage behavior in field. They were tested in the Hamburg Wheel Tracking Device, the main result of this phase was that through the ECS test it is possible to identify the good and poor performance mixtures according to the stripping failure. The aggregates that were tested are: Granite, Siliceous Gravel (poor), Siliceous Gravel (good), Chert Gravel, Limestone, Sandstone, Dolomite and Siliceous Gravel, and the asphalt used was: PG 67-22 , PG 64-22, PG 58-28, PG 67-22, PG 64-22, PG 76-22, PG 64-22 and PG 64-22 respectively.

[8] (Moraes, Velasquez, \& Bahia, 2011) found the shedding effort for different asphalts and different aggregates from the Bitumen Bond Strength-BBS test. In this research they considered the analysis of the wettability and free surface energy for the individual chosen samples. Aspects such as the balance between the adhesion and cohesion forces were found. The adhesive forces were found to be larger than the cohesive ones, and when the liquid used in the test occurs, it forms a drop and does not moisten the surface of the solid. A formula for measuring the characteristics of the wettability surface of a liquid is to measure the contact angle of a drop of liquid placed on the surface of a solid. This is done in such a way that a low surface wettability provides a high contact angle and a high wettability provides a low contact angle. [9](Figueroa, Velasquez, Reyes, \& Bahia, 2013) investigated the influence of extensive water exposure on the stripping potential of asphalt binders by measuring rheological properties, bond strength and the wettability of a Colombian binder before and after immersion in water for three, six, and nine months. In this study, thin films of asphalt (i.e. height $=2 \mathrm{~mm}$ ) were immersed in water for three, six, and nine months and comparisons were made between experimental results of unconditioned and conditioned binders. The bond strength between the binder and aggregates was measured using the Binder Bond Strength (BBS) test. The wettability potential of the conditioned and unconditioned binder was estimated using the Sessile Drop method. Experimental results indicate that there are significant changes in the properties of the binder after nine months of water conditioning. Furthermore, dynamic modulus of the mixes prepared with the binder conditioned for nine months is significantly higher than the modulus of the unconditioned mix. One of the contributions of this research measurement of adhesion, cohesion and wettability directly on the rocks. [10](Aguiar-Moya, J. P., Loría-Salazar, L. G., Salazar-Delgado, J., Hajj, E. Y., Villegas-Villegas, R. E., \& Navas-Carro, 2013) conducted an investigation to assess the 
adhesion effort of the asphalts and aggregates used in the construction of pavements in Costa Rica. Different asphalts were analyzed under the environmental effect using the BBS as a test that allows to find the variation of the detachment effort when modifying the properties of the binders. The most recent studies about adhesion and cohesion have been focused on the surface free energy of fillers,[11] (Chaturabong \& Bahia, 2018), studied the moisture damage of asphalt mixtures can be caused either by adhesive failure between asphalt binder and aggregate surface, or by cohesive failure within the asphalt mastic. They measured the effect of moisture on cohesive failure caused by asphalt mastic bonding deterioration measured by the Bitumen Bond Strength (BBS) test. This study included different mineral fillers. Results collected indicated that surface area and mineralogy of mineral fillers have important effects on moisture damage resistance.

\subsection{Thermodynamic theory}

This is also called adsorption theory and is based on the concept that an adhesive material adheres to a substrate due to established intermolecular forces provided that there is intimate contact between the surfaces. The magnitude of these forces is generally related to the thermodynamic quantities such as the free surface energy of the materials that are part of the adhesive process. The orientation of the polar molecules is part of the process to minimize the free surface energy of the aggregate-asphalt interface. Considering that thermodynamics studies energy changes, it is necessary to understand that a spontaneous process is one that occurs by itself, i.e. without external factors. These processes occur due to an imbalance between two natural tendencies. The first one is the conversion of potential energy into work and heat, also known as enthalpy, which is defined as the thermodynamic magnitude of a body and is equal to the sum of its internal energy and the product of its volume multiplied by external pressure. The second process is entropy, defined as the thermodynamic magnitude that measures the unusable part of the energy contained in a system. The relationships between the stresses of the surface of the solid, the liquid and solid-liquid interface and the contact angle were expressed by [12](Schrader,1995), through Young's equation, Eqs.(1,2). (See figure 1).

$$
\begin{array}{ll}
\qquad \gamma_{S}=\gamma_{S L}+\gamma_{L} \operatorname{Cos} \theta \\
\gamma_{S}: & \text { Surface energy of the solid } \\
\gamma_{L}: & \text { Surface energy of the liquid } \\
\gamma_{S L}: & \text { Interfacial solid-liquid energy } \\
\mathrm{Wc}=2 \gamma: & \text { Cohesion Work }
\end{array}
$$

\section{Cohesion(asphalt) Adhesion(asphalt-rock)}

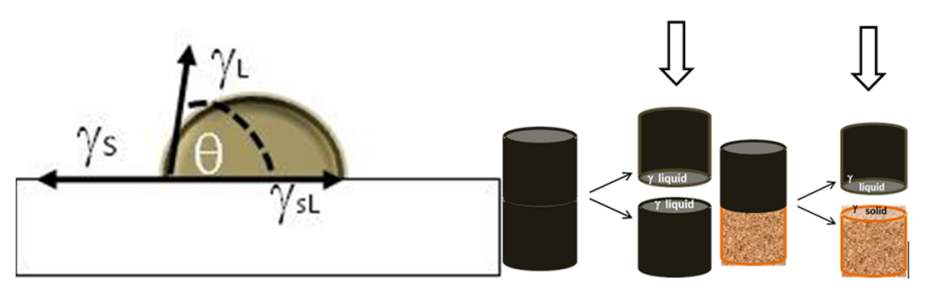

Figure 2. Contact angle to determine cohesion and adhesion

$W_{a}=W_{S L}=$ Adhesion work = Solid-liquid work (work required to separate the liquid from the surface of the aggregate). (See FIGURE 2 and FIGURE 3). 


$$
\begin{gathered}
W_{a}=W_{S L}=\gamma_{S}+\gamma_{L}-\gamma_{S L} \\
\gamma_{L} *(1+\cos \theta)=2 * \sqrt{\gamma_{S}^{L W} * \gamma_{L}^{L W}}+2 * \sqrt{\gamma_{S}{ }^{+} * \gamma_{L}}+2 * \sqrt{\gamma_{S^{-}} * \gamma_{L}{ }^{+}}
\end{gathered}
$$

Where: $\quad \gamma^{L W}$ : Lifshitz-Van Der Waals apolar component

$\gamma^{-}: \quad$ Lewis basic parameter

$\gamma^{+}: \quad$ Lewis acid parameter

$$
W_{a}=\gamma_{L}(1+\cos \theta)
$$

Where:

Contact angle is $\theta$ and it value can vary how is shown below.

$$
\begin{array}{lll}
\theta=0^{\circ} & \theta=90^{\circ} & \theta=180^{\circ} \\
W c=W a & W c=2 W a & W a=0
\end{array}
$$

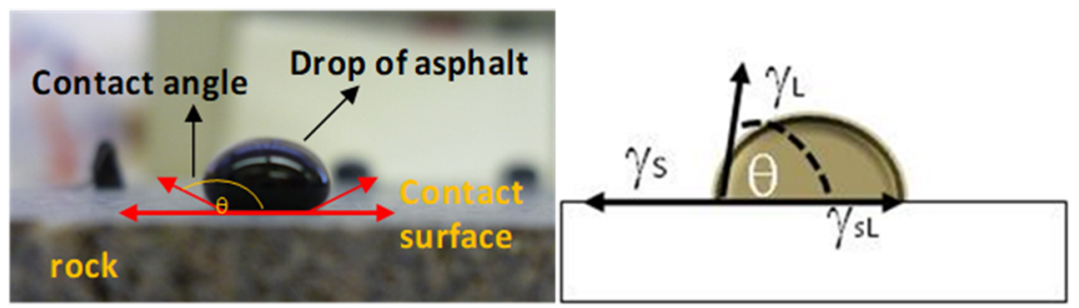

Figure 3. Contact angle rock-asphalt. (Figueroa et al., 2013)

\section{MATERIALS AND METHODS}

The asphalt binder (i.e., Pen 60-70 (0,1 mm) aT 25ㄷ, ASTM 1437 or (PG58-28)) and aggregate used in this research correspond to materials typically used in Colombia for the construction of flexible pavements. Three types of aggregates were selected: the first one was sandstone (aggregate 1) with an apparent density of 2.46 and an absorption of $3.36 \%$, the second one (aggregate 2) was extracted from Alto Laguna with an apparent density of 2.43 and an absorption of $3.33 \%$ and the third (aggregate 3 ) was from the Coello River, it is a gray alluvial origin limestone with values of apparent density of 2.74 and absorption of $0.36 \%$. The Bitumen Bond StrengthBBS test was made according to the AASHTO TP-91 standard.

The surface was visually inspected to determine the type of failure, (see FIGURE 4). The interpretation of results in this test says that if the asphalt footprint is greater than $50 \%$, the failure mode is Cohesive. On the other hand, if the footprint is less than $50 \%$, the failure mode is Adhesive.

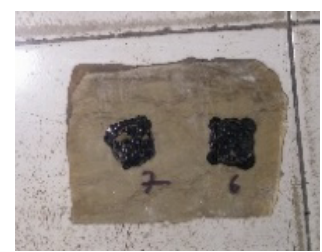

(a)

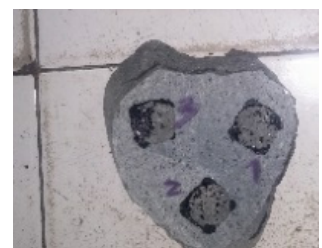

(b)

Figure 4. Typical fingerprints after BBS test, (a) Cohesive Failure, (b) Adhesive Failure

The contact angle measurement was performed according to ASTM-D7334 (8). From the contact angle measurement and the wettability, the free surface energy (ESL) was calculated according to the Sessile Drop process, (see FIGURE 5), and based on the Young-Dupre formulation. The ESL calculation was performed on the three types of aggregates to determine adhesion 
at the asphalt-aggregate interface. Additionally, the ELS of the single binder was also determined. The three reference liquids that were used were: Formamide (F), Deionized Water (H20) and Ethylene Glycol (E).

Figure 5. Running the DROP Image Advanced Software

\section{Results and Analysis}

Due to their high porosity the sandstones presented adhesive and cohesive failure while the limestones presented cohesive failure in wet conditions and adhesive in dry condition (TABLE 1), those values were estimate according to the typical fingerprints after BBS test.

Table 1 - Type of failure for each type of aggregate in dry and wet condition

\begin{tabular}{ccccc}
\hline \multirow{2}{*}{ Type of rock } & \multicolumn{2}{c}{ Dry Condition } & \multicolumn{2}{c}{ Wet Condition } \\
\cline { 3 - 5 } \cline { 3 - 5 } Aggregate 1(sandstone) & Asphalt covered area average & Type of failure & Asphalt covered area & Type of failure \\
\cline { 2 - 5 } Aggregate 2(sandstone) & $98,60 \%$ & cohesive & $96,72 \%$ & cohesive \\
Aggregate 3(limestone) & $94,92 \%$ & cohesive & $92,40 \%$ & cohesive \\
\hline
\end{tabular}

In dry conditions, the three rocks failed cohesively, showing that the adhesion forces of the Asphalt-Aggregate make upper and lower case consistent interface were greater than the internal forces of asphalt cohesion (see Figure 6Erro! Fonte de referência não encontrada.). Also, in wet conditions, the sandstones continued with this behavior, but the limestone changed the mode of failure, presenting asphalt material loss of more than $50 \%$.

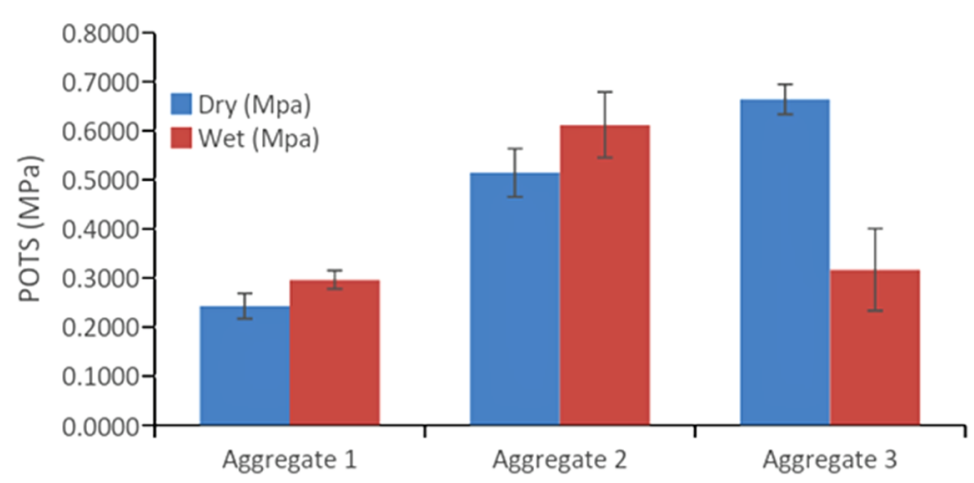

Figure 6. POTS values for three types of rocks (dry and wet condition) 
The contact angles obtained by the Sessile Drop Test are shown in (TABLE 2). The results shown in TABLE 2 indicate the contact angle obtained with the asphalt (A) on each type of aggregate. TABLE 3 shows the contact angles using the test liquids, so F, H20 and E, on each type of aggregate.

Table 2 - Angles using asphalt on the aggregates

\begin{tabular}{rcc}
\hline Type of Aggregate & Contact Angle & $\begin{array}{c}\text { Coefficient of variation (Cv) } \\
\text { (\%) }\end{array}$ \\
\hline Aggregate 1 & $155,9^{\circ}$ & 3,13 \\
Aggregate 2 & $159,2^{\circ}$ & 2,21 \\
Aggregate 3 & $161,4^{\circ}$ & 2,22 \\
\hline
\end{tabular}

The total surface free energy for each aggregate is in (TABLE 3).

Table 3 - Summary of Total Free Surface Energy(TFSE) and its Components

\begin{tabular}{|c|c|c|c|c|c|}
\hline Surface & \multicolumn{2}{|c|}{$\begin{array}{c}\text { Acid (+) and Basic (-) } \\
\text { Components (ergs/cm2) }\end{array}$} & $\begin{array}{l}\text { Acid-Basic Component } \\
\qquad \gamma^{A B}(\mathrm{ergs} / \mathrm{cm} 2)\end{array}$ & $\begin{array}{c}\text { Apolar Component } \\
\gamma^{L W} \text { (ergs/cm2) }\end{array}$ & $\begin{array}{c}\text { TFSR } \\
\gamma \\
\text { (ergs/cm2) }\end{array}$ \\
\hline \multirow{2}{*}{ Asphalt } & $\gamma^{-}$ & 0,0098 & \multirow{2}{*}{1,886} & \multirow[t]{2}{*}{8,998} & \multirow{2}{*}{10,883} \\
\hline & $\gamma^{+}:$ & 9,111 & & & \\
\hline \multirow{2}{*}{ Aggregate 1 (Sandstone 1 ) } & $\gamma^{-}$ & 56,223 & \multirow{2}{*}{14,119} & \multirow[t]{2}{*}{65,849} & \multirow{2}{*}{80,047} \\
\hline & $\gamma^{+}:$ & 0,896 & & & \\
\hline \multirow{2}{*}{ Aggregate 2 (Sandstone 2) } & $\gamma^{-}$ & 50,440 & \multirow{2}{*}{23,784} & \multirow[t]{2}{*}{78,607} & \multirow{2}{*}{102,391} \\
\hline & $\gamma^{+}:$ & 2,804 & & & \\
\hline \multirow{2}{*}{ Aggregate 3 (Sandstone 3) } & $\gamma^{-}$ & 52,161 & \multirow{2}{*}{30,459} & \multirow[t]{2}{*}{80,060} & \multirow{2}{*}{110,519} \\
\hline & $\gamma^{+}:$ & 4,447 & & & \\
\hline
\end{tabular}

As a complement, the Humidity Damage Index (HDI), which is an index of damage that classifies the asphalt-aggregate adhesion and is based on the relation of the adhesion work in dry condition and the adhesion work in wet condition [13](Bhasin et al., 2007). It was calculated, and the results are shown in (TABLE 4). A high value of HDI indicates that energy needed to generate the loss of material in the asphalt mixture is also higher. Values of HDI $>1,5$ indicate that they are mixtures highly resistant to moisture damage in the field, values between 1,5 and 0,5 , indicate that they are mixtures of medium resistance to moisture damage in the field and values under 0,5 indicate that they are mixtures highly susceptible to moisture damage in the field. According to this range of values, all types of aggregates tested in this research are highly susceptible to moisture damage in the field. Anyway, this value is an indicator of this damage, but it is not an indicator of the speed at which it is happening [14](Caro-Spinel Silvia, 2011).

Table 2 - Angles using asphalt on the aggregates

\begin{tabular}{cccc}
\hline Aggregate & Type of Aggregate & TFSE & IDH \\
\hline Aggregate 1 & sandstone $(\rho=2,46 ; A b s=3,36 \%)$ & 80,047 & 0,361 \\
Aggregate 2 & sandstone $(\rho=2,43 ; A b s=3,33 \%)$ & 102,391 & 0,410 \\
Aggregate 3 & limestone $(\rho=2,46 ; A b s=0,36 \%)$ & 110,519 & 0,421 \\
\hline$\rho:$ Apparent Density; Abs=Absorption
\end{tabular}

The relationship between Humidity Damage Index (HDI) of the asphalt-aggregate interface and Total Free Surface Energy (TFSE) for each type og aggregate is shown in FIGURE 7. 


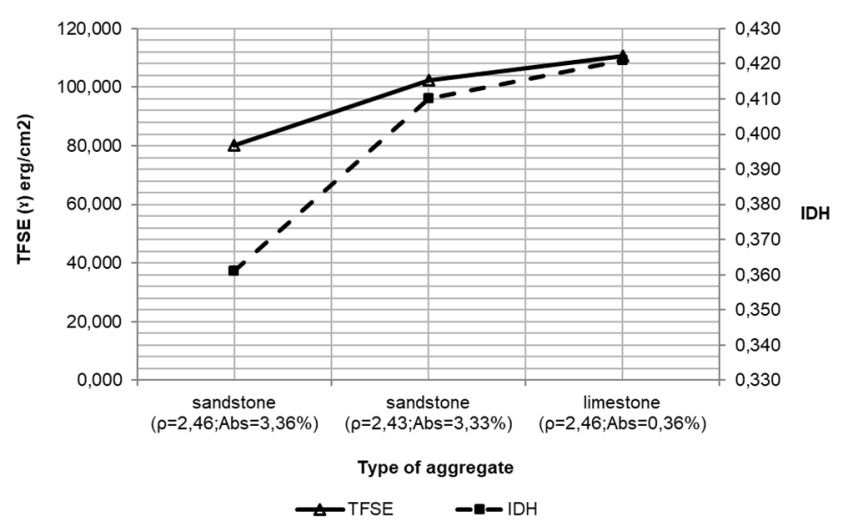

Figure 7. Relationship between Humidity Damage Index (HDI) of the asphalt-aggregate interface and Total Free Surface Energy (TFSE) for each type of aggregate

\section{CONCLUSIONS}

Absorption is a physical property of aggregates that significantly affects the asphalt-aggregate adhesion. At higher absorption, the difficulty to separate the asphalt from the aggregate, at wet condition, increases, it was the case for aggregates 1 and 2, which were high porosity sandstones.

The asphalt-aggregate interface studied showed increases in tensile strength in the Bitumen Bond Strength (BBS) test in wet conditions, compared to the tensile strength obtained in the dry condition. Although the increase in this tensile strength was not significant, it showed that water do not have any influence in the decreasing of the required release energy.

The three aggregates studied were classified according to the HDI as very susceptible to moisture. However, aggregate 2 (sandstone) had the most uniform behavior with respect to the tensile force in the BBS test, as well as a higher average of traction of detachment and less loss of asphalt in the adhesion analysis. In this way, it can be said that this last aggregate was the best to be affected by the humidity.

According to FIGURE 7, we can conclude that the mineralogy of aggregates has more influence at the Humidity Damage Index (HDI) than Total Free Surface Energy (TFSE), This phenomenon can be observed in aggregates 1 and 2, which to have similar density and absorption, but are sandstones with different origin and mineralogy.

The results obtained justify the need to carefully select the paving materials so that the asphalt-aggregate bond has a higher adhesion work in the dry state compared to the wet adhesion work to reduce the susceptibility to moisture damage of the asphalt mixture.

Because the materials studied are classified as highly susceptible to moisture damage, it is advisable to use modifiers to increase the affinity between aggregate and asphalt and to reduce water ingress to the interface.

\section{REFERENCES}

Bhasin, A., Little, D. N., Vasconcelos, K. L., \& Masad, E. (2007). Surface Free Energy to Identify Moisture Sensitivity of Materials for Asphalt Mixes. Transportation Research Record, 2001(1), 37-45. https://doi.org/10.3141/2001-05

Caro-Spinel S, Masad E, Bhasin A, Little DN. "Moisture susceptibility of asphalt mixtures, Part 1: mechanisms". Int J Pavement Eng - INT J PAVEMENT ENG. 2008;9(2):81-98

Kiggundu, B. M., \& Roberts, F. L. (1988)." Stripping in HMA mixtures: State-of-the-art and critical review of test methods" (No. NCAT Report No. 88-2). Auburn, AL: National Center for Asphalt Technology. 
Terrel, R L., Saleh A, \& Todd V. S. (2011). “Equipment and Method for Environmental Testing of Bituminous Specimens (Concesión)”. Oregon: Oregon State University.

Nicholson, V. (1932). "Adhesion tension in asphalt pavements, its significance and methods applicable in its determination (Monograph)". Highway Research board Bibliography.

McCann, M., Anderson-Sprecher, R., \& Thomas, K. P. (2005). "Statistical comparison between SHRP aggregate physical and chemical properties and the moisture sensitivity of aggregate-binder mixtures". Road Materials and Pavement Design, 6(2), 197-215.

Solaimanian, M., Fedor, D., Bonaquist, R., Soltani, A., \& Tandon, V. (2006). “Simple performance test for moisture damage prediction in asphalt concrete (with discussion)". Journal of the Association of Asphalt Paving Technologists, 75.

Moraes, R., Velasquez, R., \& Bahia, H. (2011). "Measuring the effect of moisture on asphalt-aggregate bond with the bitumen bond strength test". Transportation Research Record: Journal of the Transportation Research Board, (2209), 70-81.

Figueroa, A., Velásquez, R., Reyes, F., \& Bahia, H. (2013). "Effect of Water Conditioning for Extended Periods on the Properties of Asphalt Binders". Transportation Research Record: Journal of the Transportation Research Board, (2372), 34-45.

Aguiar-Moya, J. P., Loria-Salazar, L., Salazar, J., Villegas, E., Corrales-Azofeifa, J. P., Hajj, E. Y., \& Center, W. R. S. (2013). Evaluation of Adhesion Properties of Costa Rican Asphalt Mixtures using the Bitumen Bond Strength (BBS) and Contact Angle Measurement Tests. En 92th Annual meeting of the transportation research board, Washington, USA.

Chaturabong, P., \& Bahia, H. U. (2018). Effect of moisture on the cohesion of asphalt mastics and bonding with surface of aggregates. Road Materials and Pavement Design, 19(3), 741-753.

Schrader, M. E. (1995). Young-dupre revisited. Langmuir, 11(9), 3585-3589.

Bhasin, A., Little, D., Vasconcelos, K., \& Masad, E. (2015). Surface free energy to identify moisture sensitivity of materials for asphalt mixes. Transportation Research Record: Journal of the Transportation Research Board, 2001, 37-45.

Caro-Spinel, S., \& Alvarez-Lugo, A. E. (2011). Evaluación de la susceptibilidad al daño por humedad de mezclas asfálticas empleando propiedades termodinámicas. Revista Facultad de Ingeniería, (58), 95-104. 